\title{
$O$ enigma da arte de massa: Seria a distinção entre "alta" e "baixa" arte ainda relevante para a interpretação da Obra de Arte?
}

\section{The Riddle of Mass Art: is the Distinction Between 'High' and 'Low' Art still Relevant to the Interpretation of the Work of Art?}

Prof. Dr. Paolo D’Angelo

paolo.dangelo@uniroma3.it

Università di Roma Tre, Itália

tradução Paulo Gil Ferreira

paulocesarovich@gmail.com

Eu gostaria de começar por dois livros recentes. O primeiro é o volume póstumo de Eric Hobsbawm, Tempos Fraturados, publicado em 2012; o segundo, a mais recente obra de Mario Vargas Llosa, A civilização do espetáculo, que saiu no início deste ano, 2013. É difícil imaginar dois autores mais diferentes. Eric Hobsbawm é o grande historiador do século XX, o inventor do "breve século", um escritor tenazmente ligado em suas análises ao pensamento marxista, o qual ele continuou a reafirmar mesmo após a queda do muro de Berlim. Vargas Llosa é o famoso escritor peruano, autor de $A$ cidade e os cachorros, mas também um político liberal que, quando seu país de origem decidiu nacionalizar o Banco Central, entrou na arena política, concorrendo como candidato a presidente com o objetivo de salvaguardar o mercado livre. Eu acho que é justo dizer que Hobsbawm e Vargas Llosa iriam diferir e, de fato, assumir visões diametralmente opostas em quase todos os temas históricos recentes.

Caso lhes perguntássemos por uma previsão ou uma indicação do futuro, está claro que eles olhariam em direções antitéticas. Caso eles tomassem parte em um debate político direto, temo que seria difícil para eles encontrar qualquer denominador comum.

E, mesmo assim, quando lidamos com a situação da arte, quando a questão que deve ser respondida versa sobre a evolução das artes ocorrida no século XX e sobre o que trará o novo milênio, suas posições não mais se chocam. Suas diferenças desaparecem, e o marxista determinado, como só certos marxistas ingleses sabem ser, caminha de mãos dadas com o defensor do liberalismo. $\mathrm{Na}$

*Apresentado originalmente em: VI Congresso Internacional “Questões Fundamentais da Hermenêutica Filosófica:

"A Hermenêutica da Obra de Arte"" - UERJ/Brasil [2013]. 
verdade, ambos estão profundamente convencidos de que a arte, ou que as artes deslizaram para uma crise que não pode ser detida. Eles acreditam que as artes, tal como as conhecemos e amamos ao longo de séculos, ou pelo menos ao longo da história moderna, já desapareceram. O que sobrevive são apenas fantasmas e fantasmas são aparições da morte. As artes na forma em que as conhecíamos desapareceram literalmente. $\mathrm{O}$ que as fez desaparecer, o que as matou, foi outra arte, ou outras artes, que nada teriam a ver com arte ou artes, exceto pelo fato de que elas usurparam o nome, sendo na realidade algo completamente diferente: indústria, bens, entretenimento, mercadorias. $\mathrm{O}$ que fez a arte desaparecer foi a arte de massa, que sacrificou os ritos sagrados da alta arte em favor das orgias da baixa arte, a qual, dito rigorosamente, não é de forma alguma arte.

Hobsbawm escreve uma elegia para o desaparecimento da grande arte burguesa, que gozou de seus mais grandiosos momentos no século XX e que teve seus templos nas galerias e salões, nas óperas e nos teatros, nas salas de concerto e nas bibliotecas. Os esforços da vanguarda do século XX para preservar o papel da arte na sociedade falharam. Hobsbawm (nascido em 1917, morto em 2012) foi um visitante frequente desses palácios durante sua vida, mas quando ele olhava à sua volta, ele via apenas pessoas velhas, europeus e esnobes, e ele tomava isto como prova de que este era, muito literalmente, o mundo de outrora. O presente está em outro lugar, o desenvolvimento da sociedade inundou nossas vidas com infinitas experiências auditivas, visuais e verbais, as quais não têm, contudo, nenhuma conexão com aqueles produtos do que consideramos como artes tradicionais, com seu status privilegiado de pedras de toque do bem e do mal, portadores de valores como verdade, beleza e catarse ${ }^{1}$.

Vargas Llosa não é mais conciliador, tampouco ele é mais otimista. Para ele também, a arte e, com ela, a "alta cultura", se foi. Em seu livro, ele protesta contra "o desaparecimento da alta cultura, obrigatoriamente minoritária pela complexidade e às vezes pelo hermetismo de suas senhas e códigos", e contra a massificação da ideia mesma de cultura ${ }^{2}$. O desaparecimento da cultura significa primeiramente o desaparecimento da arte como a conhecíamos durante séculos:

A imensa maioria do gênero humano não pratica, consome, nem produz hoje outra forma de cultura que aquela que, antes, era considerada pelos setores cultos, de

1 HOBSBAWM, E. Fractured Times: Culture and Society in the Twentieth Century, Little, Brown: 2013, Preface.

2 VARGAS LLOSA, M. La civilización del espectáculo, Madrid, Prisa, 2012, p. 35. 
maneira depreciativa, como mero passatempo popular, sem parentesco algum com as atividades intelectuais, artísticas e literárias que constituíam a cultura. Esta já morreu, ainda que sobreviva em pequenos nichos sociais, sem influência alguma sobre o mainstream. ${ }^{3}$

$\mathrm{O}$ anátema contra a arte de massa parece realmente unir essas figuras irreconciliavelmente opostas. Vargas Llosa, por exemplo, tem que arrumar um jeito de mostrar que sua análise difere daquela do revolucionário escritor marxista de vanguarda Guy Debord, em seu famoso A sociedade do espetáculo (1967). O fato de o título do pai do situacionismo e o do escritor peruano serem substancialmente o mesmo diz muito sobre como convergentes são as análises, se não em seu tom, pelo menos em seu objetivo polêmico.

Outras convergências, nunca tornadas explícitas por Hobsbawm ou Llosa, no entanto, deviam causar embaraços ainda mais reais. É bem evidente, na verdade, que uma longa sombra pode ser vista, uma sombra que fornece a fundação, o arcabouço teórico, e às vezes até mesmo o léxico por trás dos discursos de ambos os autores.

Refiro-me, como vocês devem ter percebido, às obras de Theodor Wiesengrund Adorno, especialmente, àquilo que encontramos na terceira parte da Dialética do Esclarecimento, e àquelas de Walter Benjamin, especialmente em $A$ obra de arte na era de sua reprodutibilidade técnica. Do primeiro, tanto o historiador quanto o escritor, adotam a crença de que a produção em massa traz para a cultura as características da produção industrial em geral e, inevitavelmente, concebe produtos padronizados e intercambiáveis, cujo único propósito é o entretenimento; do segundo, eles adotam a pressuposição de que na raiz de tudo reside a possibilidade de reprodução virtualmente infinita. Isto priva a obra de sua singularidade e de sua "aura" e leva o espectador a usufruí-la de maneira distraída.

Poder-se-ia explorar longamente as diferenças nas leituras da arte de massa nas obras de Benjamin e Adorno. Elas estão evidentes, dentre outras coisas, nas cartas que eles trocaram nos anos que antecederam a escrita de suas grandes obras. Mas não é isso que nos interessa aqui. O que é consideravelmente interessante é a era em que eles formaram suas teses. A razão para isso é facilmente explicável, mesmo que isto precise ser feito em linhas gerais. É estranho que textos escritos em uma situação histórico-política tão particular há quase cem anos atrás (permitam

I Ivi, pp.30-31. 
que eu me corrija, noventa), ainda ofereçam o arcabouço, a substância e o tom das análises atuais: ainda assim, isto é exatamente o que acontece, não apenas com Hobsbawm e Vargas Llosa, mas também, por exemplo, com muitos estudos de arte de massa concebidos no interior dos chamados Estudos Culturais.

Isto é estranho, não simplesmente porque as técnicas de reprodução, a natureza das obras e seu público, bem como as próprias artes envolvidas no processo de industrialização e massificação tenham mudado. Não há duvidas quanto a isto; identificar essas mudanças será a tarefa que realizaremos no decorrer da fala de hoje. Mas para começar, deixemo-nos vislumbrar uma diferença preliminar que não é facilmente subestimável: tanto Benjamin quanto Adorno, o primeiro diretamente e o segundo indiretamente, tinham em mente, quando discutiam arte de massa, a massificação das artes induzida e causada pelo totalitarismo do século XX, as funções das artes de massa na Alemanha nazista e na Rússia stalinista. É verdade, é claro, que Adorno estava escrevendo nos Estados Unidos e era influenciado pela indústria cultural americana ${ }^{4}$; mas isto foi apenas um subterfúgio que ele utilizava para comparar com aquilo que ele via e que estava acontecendo em seu próprio país, tanto antes quanto depois da chegada de Hitler ao poder. Precisamos reconhecer, destarte, que o que veio a acontecer não foi, felizmente, a alternativa militante proposta por Benjamin, que via apenas a estetização da política, por um lado, e a politização da arte por outro. Evidentemente que o modelo de arte de massa com o qual tivemos de lidar na segunda metade do século XX não está tão essencialmente a serviço de ditaduras, mas lidamos com aquele cuja função está colocada no interior dos regimes liberal-democráticos de sociedades avançadas. Foi no interior desses sistemas e dessas culturas que as artes de massa prosperaram e tiveram seus efeitos, constituindo em termos quantitativos, sem dúvida, o mais notável fenômeno cultural da época recente, apenas comparável em suas consequências ao enorme aumento nos níveis de educação mediana, o que constitui o outro fenômeno de longa duração que caracterizou, em nível cultural, o desenvolvimento dessas sociedades.

Pela primeira vez na história estamos lidando com populações quase todas elas com acesso à educação básica e um percentual sempre maior delas possui a oportunidade de continuar até a educação superior. Mesmo que isto só seja

4 Adorno sabe bem que "o sistema da indústria da cultura vem das nações industriais mais liberais; e toda sua mídia característica, tais como cinema, rádio, jazz e revistas florescem ali" (HORKHEIMER, Max; ADORNO, Theodor W. Dialectic of Enlightenment, New York: Continuum, 1998, p. 132), mas o termo de comparação de sua posição permanece a Alemanha Guilhermina: "Na Alemanha o fracasso do controle democrático em permear a vida tinha levado a uma situação paradoxal. Muitas coisas foram dispensadas do mecanismo de mercado que havia invadido os países ocidentais. [...] Isto fortaleceu a arte nessa fase tardia contra o veredito da oferta e da procura", pp. 132-133. 
raramente levado em consideração em análises de artes de massa, creio ser primordial manter a atenção na correlação entre arte de massa e educação de massa: isto nos ajudará a explanar a questão da arte de massa em termos menos afetados e mais sóbrios, evitando o esnobismo que está sempre relacionado àqueles que falam sobre artes "baixas".

Se nos perguntarmos o que é arte de massa hoje em dia, os esclarecimentos necessários para uma delimitação preliminar do campo parecem ser tantos que corremos o risco de falar apenas sobre estes e nunca chegar à questão de seu $p a-$ pel e significado. Parafraseando o famoso incipit de Adorno, já ficou óbvio que nada relacionado à arte de massa é óbvio, e que não é nem mesmo óbvio que deveríamos chamá-la de arte de massa. Quando o Journal of Aesthetics and Art Criticism dedicou um número especial ao tópico em 1999, ele adotou o termo arte popular. Outros autores falam sobre este tema usando a dicotomia "alta e baixa arte", frequentemente complicada pela adição de um terceiro termo, tirado do outrora famoso artigo de McDonald que distinguia entre alta-, média- e baixa intelectualidade. As duas descrições de arte de massa contidas no Oxford Handbook of Aesthetics e no Routledge Companion to Aesthetics falam respectivamente da "Estética da Arte Popular" e da "Alta Arte versus Baixa Arte". Outros autores, por exemplo, R. Shusterman, preferem falar de Arte de Entretenimento. Em geral, a correção política adverte contra o uso do termo arte de massa, pois ele é visto como sendo depreciativo e, em vez dele, favorecem o termo arte popular. Todavia, isto coloca um problema imediato, porque a arte popular sempre existiu, enquanto a arte de massa é um fenômeno inteiramente do século XX (exceto no caso da literatura, na qual a arte de massa existe desde o século XIX). Além disso, o termo popular parece estar tão desgastado dentro dos Estudos Culturais que ele só pode ser circunscrito com dificuldade.

No mundo anglófono, há uma saída para isto no termo "Arte folk", arte criada e consumida pelas camadas menos cultas da população. Porém, em outras línguas europeias, o uso do termo popular complica por demais as coisas, pois se formou em torno do termo uma estratificação de quase três séculos, por exemplo, na Alemanha e na França, do völkisch de Herder ao nazional-populare de Gramsci. Qualquer um que deseje aprofundar-se nisso pode consultar o verbete "Populär/volkstümlich/Popularkultur" no Ästhetische Grundbegriffe de H. Barck. Por fim, o termo indústria cultural, escolhido por Adorno, hoje em dia aparece como um termo que ensejou confusão. Nas intenções de seu criador, supunha-se que ele tivesse tornado imediatamente claro que a arte de massa não é um produto das massas, mas uma arte produzida serialmente por uma máquina tecno-industrial com a intenção deliberada de manipular as mesmas massas. De 
fato, uma área que eu chamaria de comunicação social por meio de produtos industriais tem ganhado mais e mais força em nossas sociedades, muito mais do que a reprodução técnica de obras de arte em sentido estrito, e ela é mais merecedora do termo indústria cultural. Esta esfera da comunicação social pode ser vista no design de objetos domésticos, na propaganda, moda, turismo, no mundo do entretenimento, e, certamente, na culinária. Na medida em que esses segmentos de produção, somados a sua função prática, desempenham um papel comunicativo igualmente indispensável, penso ser oportuno reservar o termo indústrias culturais para eles e usar o termo arte de massa apenas no sentido estrito ${ }^{5}$.

Portanto, proponho dois movimentos forçados e arbitrários para nos habilitar a levar a questão adiante. Em primeiro lugar, eu não vou lidar com o problema da ligação entre artes de massa e indústrias culturais no sentido em que acabei de defini-las; em segundo lugar, eu partirei de uma definição esquemática de arte de massa, a qual pode ser encontrada na Filosofia da Arte de Massa de Noël Carroll. Utilizá-la-ei a fim de indicar as mudanças vitais que ocorreram nas artes de massa nas décadas recentes. No mais, reservar-me-ei o direito, na medida em que avançarmos, de fazer um comentário adicional acerca da definição de Carroll.

Tomemos, portanto, a definição de Carroll, que, na maneira tradicional da estética analítica, pretende-se como uma definição apenas dentro de condições estritamente limitadas. Para Carroll, uma obra de arte X é uma obra de arte de massa se e somente se:

1) X é uma obra de arte de exemplares múltiplos ou em espécie;

2) Produzida e distribuída por uma tecnologia de massa;

3) Em cujas escolhas estruturais a obra de arte está intencionalmente projetada para gravitar (por exemplo, em suas formas narrativas, simbolismo, efeito pretendido, e mesmo seu conteúdo); em função daquelas escolhas que prometam acessibilidade com mínimo esforço, virtualmente no primeiro contato, para o maior número de audiências não iniciadas (ou relativamente não iniciadas).

De maneira geral, a primeira condição parece a mais óbvia. Se nós formos falar de arte de massa, então a obra de arte precisa ser reprodutível, isto é, ela precisa ser uma obra cujos exemplares individuais podem ser vistos como

5 Para uma discussão desses fenômenos, cf. LIPOVETSKY, G ; SERROY, J. L'esthétisation du monde. Vivre à l'âge du capitalisme artiste, Paris, Gallimard, 2013. 
representando uma espécie. Para usar a terminologia de Nelson Goodman ou Genette, ela precisa ser o produto de uma arte alográfica e não de uma arte autográfica, isto é, de uma arte na qual a história da produção da obra não seja relevante para seu status enquanto obra, e na qual não haja falsificações, que fossem duplicatas da mesma obra de arte. Isto pode parecer abstruso, mas pode ser explicado por meio de exemplos. Um romance pode ser impresso em milhares ou mesmo milhões de cópias, pois sua identidade é a identidade simples de seu próprio texto. É irrelevante se ela é uma edição simples ou de luxo, com uma fonte maior ou menor, ou mesmo se é uma tradução. A mesma coisa vale para as cópias de um filme, que podem ser rolos de filme, DVDs ou bytes em um site da internet, mas que são sempre cópias deste filme em particular; isto vale também para trechos de música que podem ser reproduzidos milhões de vezes, ou mesmo, como o Gangnam Style, bilhões. A situação com pinturas é diferente. O Incêndio do Borgo é o único afresco de Rafael pintado em uma parede em uma das câmaras da Torre Borgia no Vaticano. Qualquer outro exemplar do mesmo afresco, mesmo que ele tenha exatamente as mesmas dimensões, as mesmas cores e assim por diante, não é a pintura de Rafael, mas uma cópia dela.

Esta condição, se ela for válida, limita decisivamente o âmbito da arte de massa: se nós a seguirmos, pode haver arte de massa literária, musical e cinematográfica, mas não pode haver obras de arte figurativas de massa. Mesmo obras de arte figurativas, como gravuras e esculturas, podem ser reproduzidas em números menores (eu posso produzir centenas de aquarelas a partir do mesmo cliché, mas não milhões, e talvez seja tecnicamente possível fazer milhões de exemplares de Os Burgueses de Calais de Rodin, mas isto não pode ser sustentado economicamente). E assim foi de fato por um longo tempo. A primeira arte de massa foi a literatura. Ela ganhou o potencial de vir a sê-lo com a invenção da máquina de impressão, mas na prática ela só se estabeleceu com o folhetim do século XIX: o "Conde de Montecristo", "Os Três Mosqueteiros", ou "Beati Paoli", todos são exemplos muito bem acabados da arte de massa do século XIX. E, deve-se acrescentar, eles vieram a sê-los, porque o número de leitores potenciais nos grandes países europeus (Alemanha, Grã-Bretanha, França) cresceu exponencialmente durante o século XIX (frequentemente crescendo até mais da metade da população; como meio de comparação: na época da unificação da Itália, em 1860, 79\% da população ainda era analfabeta; hoje, a taxa estimada de analfabetismo no mundo inteiro é de 18\%. Naturalmente que a leitura de um romance requer mais do que alfabetização primária, portanto, seria necessário concentrar-se naquela parte da população com nível de educação de médio a superior). 
Após a literatura, fotografia e cinema tornaram-se artes de massa, pois podiam ser reproduzidas em muitos exemplares idênticos; ao mesmo tempo, a capacidade técnica de reproduzir a música evoluiu (inicialmente ela era reprodutível, mas apenas, digamos, de um modo mais caseiro, isto é, por meio da presença direta da pessoa executando a música); finalmente, meios individuais de reprodução entraram em uso: primeiro rádio e televisão; depois computador e outros utensílios eletrônicos. As artes visuais tradicionais (a pintura, em suas várias formas, a escultura, a arquitetura) permaneceram excluídas de tudo isto, por causa do estatuto ontológico de suas obras. Mas será que é mesmo assim? A massificação da arte realmente diz respeito apenas às artes visuais nas formas "tecnicamente reprodutíveis" no sentido tradicional? Permita-me expressar certa dúvida de que seja realista o quadro da situação corrente da arte de massa, que a priori excluiria a pintura e a escultura. Permita-me acrescentar alguns números. Se pegarmos a lista das galerias de arte mais visitadas no mundo, descobrimos (os dados referem-se a 2012) que há mais de cinquenta museus que atraem mais de um milhão de visitantes; que cinco museus atraem mais de cinco milhões; que a soma total de visitantes aos cinquenta museus mais frequentados facilmente excede cem milhões. Se olharmos para as exibições temporárias, encontramos igualmente altas cifras: em 2011, a exibição de Monet no Grand Palais foi visitada por algo em torno de um milhão de pessoas, enquanto a exibição do expressionismo abstrato atraiu um número consideravelmente maior. A exibição de Escher ano passado no Rio teve mais de meio milhão de visitantes. Se adicionarmos a tudo isto a onipresença de reproduções de arte de qualidade cada vez maior e ainda mais amplamente disponíveis, incluindo aquelas em formas digitais, creio que seja difícil negar que a distinção entre arte reprodutível e não reprodutível não é mais uma distinção ontológica, mas sim uma distinção entre artes (e obras) que estão ao alcance de um público amplo e artes (e obras) que não estão. Em suma: algumas grandes pinturas dos séculos XIX e XX pertencem muito mais à arte de massa do que a poesia. Mesmo que a poesia possa ser reproduzida ad libitum, e facilmente divulgada por meio da internet, ela interessa apenas a um número altamente restrito de leitores (na Itália, algumas centenas ou, no máximo, alguns milhares).

Em outras palavras, nós realmente precisamos entender que todas as artes e não apenas aquelas que têm sido tradicionalmente consideradas como tais podem agora ser consideradas artes de massa. É claro, é fácil imaginar a objeção: pisar no Louvre não é a mesma coisa que entender de Chardin, visitar a Uffizi como turistas não significa que se viu adequadamente o Doni Tondo de Michelangelo. Certamente, não há dúvida. Se tivéssemos tempo, eu poderia mostrá-los 
as interessantes estatísticas produzidas por um pesquisador italiano, Francesco Antinucci, sobre o uso dos museus. Eu poderia assinalar, por exemplo, que apenas um por cento dos visitantes de uma galeria importante se lembram de mais do que três das obras vistas, e que a grande maioria dedica no máximo cinco segundos àquelas obras em que mais se concentram. Tudo verdade, naturalmente. Porém, à parte o fato de que comprar um romance ou baixar música não significa necessariamente que se o leu ou se a ouviu, ou, acima de tudo, que se as compreendeu, um fato metodológico fundamental permanece: não parece correto comparar a experiência indubitavelmente pobre e elementar do visitante mediano de uma galeria de arte com, por exemplo, o gosto sofisticado de um espectador especializado: se há apenas trinta ou quarenta anos atrás, o número de visitantes era muito inferior ao de hoje, evidentemente, a comparação deveria ser feita com relação àqueles que anteriormente não tinham acesso algum a museus e galerias. Se este não for o caso, caímos novamente naquilo que eu chamaria de distorção adorniana: Adorno pensava pobremente no pobre diabo que escutava Beethoven de graça no rádio, ao compará-lo com o espectador que pagava para ir e escutá-lo na sala de concerto, esquecendo que o primeiro, sem o rádio, simplesmente nunca teria ouvido a respeito de Beethoven, pois ele nunca teria ido a um auditório. O paralelo com a educação obrigatória é útil: na medida em que tornar a educação disponível para mais pessoas inevitavelmente rebaixa o nível geral, todos comparam hoje em dia o nível educacional de milhões de pessoas com o de milhares ou das poucas centenas de milhares que antes chegava à educação superior, e ninguém os compara com os milhões que antes estavam excluídos.

Se paradoxalmente a proliferação e desenvolvimento de meios técnicos de reprodução, bem como a tendência para a ubiquidade, tornam os requisitos técnicos para a reprodutibilidade menos importantes, dado que agora todas as artes podem ser reproduzidas com facilidade crescente (talvez, este requisito seja mais importante em outro sentido para o qual atentaremos mais tarde). Por isso, podemos deixar de lado o segundo ponto da definição de Carroll ("produzido e distribuído por uma tecnologia de massa") e partirmos para o terceiro.

Este, como vocês se recordarão, diferentemente dos outros dois, que são dispostos em termos simples, é muito mais longo e muito mais truncado, muito mais específico e condicional. A razão é clara. Este ponto na definição de Carroll atinge o cerne da questão, que é a natureza da arte de massa. Enquanto estamos lidando com assuntos técnicos, as coisas são ou parecem ser simples. Porém, quando mudamos o discurso para o conteúdo e a forma, tudo se torna menos claro e mais difícil. Todos concordamos, eu creio, que os meios técnicos que permitem a disseminação simultânea de uma obra em diferentes lugares 
não sinaliza apenas que nós estamos lidando com arte de massa. Na verdade, tanto A Idade do ouro de Buñuel quanto Kramer versus Kramer pertencem a este categoria, assim como trechos de música compostos por Stockhausen ou gravados por Madonna, ou romances de Thomas Mann, ou de Dan Brown. Na opinião de Carroll, o que é preciso é uma obra que seja "prontamente acessível": "A Arte de Massa é projetada para ser fácil, para ser prontamente acessível, com o mínimo esforço, para o maior número de pessoas possível" (CARROLL, 1998, p. 192).

Infelizmente, não é tão fácil assim saber o que é fácil. E a situação corrente nas chamadas artes de massa torna ainda mais difícil decidir o que é fácil. Por exemplo, a condição de Carroll elimina imediatamente um aspecto que, embora não seja qualitativamente predominante, não pode, contudo, ser posto de lado. Estou me referindo ao que eu definiria como a distribuição da "alta" Arte de Massa. Tomemos a título de exemplo O Grande Gatsby. Ora, o romance de Scott Fitzgerald certamente não é Arte de Massa. Talvez ele não seja A morte de Virgílio de Hermann Broch, mas ainda assim é literatura séria. Pois bem, graças ao filme de Di Caprio e acima de tudo ao fato de que uma editora italiana decidiu republicá-lo por apenas 99 cents (o preço de um café), o livro liderou as listas de best-sellers por semanas. Como de costume, nem todo o mundo o terá lido, novamente, menos ainda o terá entendido, ainda assim, ele entrou em lares nos quais um romance contemporâneo não era comumente visto. E este não foi um caso isolado: as chances de encontrar música séria, cinema de qualidade, boa literatura, são, sem dúvida, muito maiores do que eram em qualquer tempo no passado.

Todavia, se isto não acontece, ou se isto acontece apenas em uma pequena escala, isto é porque a demanda (por música séria, cinema de qualidade e boa literatura) é ainda problemática. Na medida em que o percentual de pessoas em posse do tipo de cultura necessária para tal consumo ainda é limitado, mesmo nos chamados países avançados.

Mas deixemos de lado a distribuição em massa de "alta" arte, como um caso particular. Permanece o fato de que não é mais tão verdadeiro (talvez nunca tenha sido) que toda arte de massa seja caracterizada pela simplicidade de suas estruturas formais e a banalidade de seu conteúdo.

Peguemos o caso da música ouvida por jovens: nos últimos cinquenta anos pelo menos, ela tem sido, em muitos casos, de alta qualidade, tanto em termos de sua estrutura musical quanto de suas letras. Além do mais, há muito tempo que ela deixou de atrair apenas uma única geração de consumidores: Bob Dylan ou Janis Joplin ainda são ouvidos mesmo que eles já tenham sido ouvidos há 
quarenta anos. Outro exemplo poderia ser aquilo que na Itália é considerado como best-seller de qualidade: uma obra como O Nome da Rosa vendeu dez milhões de cópias ao redor do mundo, mas ela certamente não poderia ser chamada de fácil.

Como sempre, no caso da arte, as coisas são simples se olharmos para os extremos: todos concordamos, eu creio, que um filme de Peter Greenaway é mais dificil (mas talvez fosse melhor dizer: mais rico, mais sutil, mais profundo) do que um produto de Wollywood; contudo, para pegar outro exemplo, de que maneira Twin Peaks é mais simples do que um filme de De Sica como Umberto D.? Aqui, eu creio, incorremos em outro dos mitos adornianos que não parecem mais reais: aquele da absoluta intercambialidade dos produtos de massa. Relembre o que diz Adorno:

(...) o fato de que a diferença da série da Chrysler e dos produtos da General Motors é basicamente ilusório acomete qualquer criança com um arguto interesse em variedades. O que connoiseurs discutem como pontos bons ou maus serve apenas para perpetuar a aparência de competição e o âmbito de escolha. O mesmo se aplica às produções da Warner Brothers e da Metro Goldwyn Mayer, mas mesmo as diferenças entre os modelos mais caros e mais baratos expostos por uma mesma firma diminui constantemente: no que se refere a automóveis ${ }^{6}$.

Para ser honesto, não estou certo de que os consumidores concordariam. Com relação a carros, se um modelo lançado é ruim, nenhuma campanha publicitária, não importa quão efetiva, pode salvá-lo. E investimento maciço e planejamento caem naquilo que Adorno considera serem detalhes insignificantes. E se isto é verdadeiro para carros por que não deveria ser verdadeiro também para produtos de arte de massa? Seria muito estranho, não seria, se, enquanto os mercados consumidores se tornam cada vez mais segmentados e categorizados, o único campo no qual bens de consumo são polarizados como altos ou baixos fosse aquele de consumo cultural? Voltaremos a isto.

Até agora, olhamos para os fenômenos de arte de massa do ponto de vista das obras e de sua natureza. Entretanto, não alcançaríamos resultados dissimi-

6 ADORNO, pp. 133-134. 
lares se olhássemos para o modo como elas são usadas. Não há dúvida de que "altas" e "baixas" obras de arte existem juntamente com públicos "refinados" e "populares" (Ted Cohen insiste mais do que ninguém neste ponto). Se as "altas" obras fossem apenas para consumidores "refinados" e as "baixas" para consumo popular, não haveria nenhuma dificuldade em particular. Mas todos nós sabemos que isto não é assim.

Também neste caso, há uma exceção óbvia, representada pelo que podemos chamar de alto consumo de "baixa arte". Paladares sofisticados, connoisseurs de arte rara, frequentemente também têm a arte de massa em alta conta. Isto é evidente no caso do cinema, no qual cinéfilos ferrenhos podem curtir os irmãos Cohen, mas também Spielberg e Zemeckis. Mas está claro que este também é o caso com a música, onde sérios experts em Bach também ouvem o jazz que Adorno vilipendiava. Certamente, é muito fácil perceber que o contrário é muito menos verdadeiro: eu duvido muito que muitos fãs de Alain Resnais possam ser encontrados entre espectadores de filmes de suspense ou que leitores de Grisham voltem-se para Joyce como um refúgio da leitura de romances policiais. Da mesma forma, não podemos excluir exemplos de "alta" arte que conseguem prender a atenção de um público mais amplo, como acontece por vezes na esfera literária (como foi o caso na Itália com o romance de Elsa Morante, A História, e com os romances de Kundera na Europa; no campo do cinema, vêm à mente, cineastas como Kubrick e Hitchcock, diretores de elite que eram capazes de atrair um público mais geral). Qualquer que seja a estatística para essa osmose entre alto e baixo, o que é certo é que, dito de maneira geral, a interpenetração de diretores artísticos, o intercâmbio entre alto e baixo, a recuperação do trash em filmes Cult, são todos fenômenos típicos da cultura da última década e muito diferentes do que acontecia antes, mesmo que, é preciso que se diga, sempre tenha havido certa quantidade de movimentos de "baixo" para o "alto", somada à mais óbvia transferência do alto para o baixo. (Pode-se pensar no impacto de formas populares de espetáculo como o vaudeville ou o teatro de revista no cinema nascente ou, mesmo antes disso, do romance moderno no sistema literário entre os séculos dezoito e dezenove). Qualquer um que queira ter um índex disso, se bem que resumido, pode conferir obras como Pós-modernismo de Frederic Jameson, na qual o tema do intercâmbio entre diferentes níveis culturais é um dos principais fios condutores.

Constitui um erro, creio eu, insistir em falar apenas sobre "alto" e "baixo". Tal insistência pode nublar o que é provavelmente o principal fenômeno com o qual estamos lidando: a prevalência do produto de arte mediano. 
Peguemos a produção literária e cinematográfica. O que é gritante é a presença de grande quantidade de produtos que podem ser colocados, como eram, no meio caminho entre uma obra de puro entretenimento de massa e uma obra elitista. Não seria correto estigmatizar esses produtos tão apressadamente, porque eles frequentemente contêm ideias que não são banais e introduzem personagens e psicologias que não são inteiramente estereotipadas etc. É claro, o produto artístico mediano, o infame Midcult, foi a bête noire dos teóricos da arte de massa.

Dwight McDonald, quando lida com o Midcult no seu livro de 1960, Masscult e Midcult, nuca teve uma coisa boa a dizer a respeito dele. Ele o desprezava muito mais do que a honesta arte de massa. Esta abordagem não seria possível hoje, pela simples razão que muito do que é publicado, lido, assistido e ouvido pertence ao Midcult. McDonald estava trabalhando no interior de um arcabouço completamente diferente. Seu ponto de referência ainda era a vanguarda, por um lado, e a arte de massa, por outro. Não há absolutamente nada de estranho nisso, pois a final de contas, arte de vanguarda e arte de massa são, em última análise, nada mais do que dois lados da mesma moeda. Elas servem como polos dentro do mesmo sistema de valores. Querem uma prova disso? Releiam o ensaio de Clement Greenberg "A vanguarda e o Kitsch" e vocês verão que a vanguarda é a pedra de toque para a arte de massa, não por acaso identificada por Greenberg com o puro e simples mau gosto estético (e McDonald acompanha-o nisso, identificando o Kitsch com o Midcult).

Entrementes, podemos começar a extrair algumas conclusões. A vanguarda acabou, e ela acabou, estranhamente, após a Segunda Guerra Mundial, isto é, na era da afirmação da arte de massa. As chamadas vanguardas da segunda metade do século XX foram sobrevivências patéticas que, enquanto reclamavam serem lideranças inovadoras, na verdade, ficavam à vontade com a tradição. As vanguardas não estão inteiramente atrás de nós, e isto não quer dizer, contrariamente ao que pensa Arthur Danto, que a história da arte acabou. Na verdade, isto sugere que a fase na história da arte, que provavelmente começou com o Romantismo, chegou ao fim. O que é verdade, contudo, é que, se a vanguarda acabou, então, precisamos também repensar a arte de massa: em um sistema bipolar um termo não pode permanecer inalterado se o outro sai de cena. $\mathrm{O}$ erro cometido por muitos teóricos contemporâneos da arte de massa, os principais dentre eles, os seguidores de Adorno (ninguém, mais do que Adorno, insistia tanto na oposição entre a vanguarda e a arte de massa), é continuar a pensar na arte de massa em termos de sua relação dialética com a arte de vanguarda. Carroll: "da mesma forma que a vanguarda é a antítese da arte de massa, isto proporciona, de maneira hegeliana, um insight com relação à 'tese', a arte de massa, contra a qual ela dirige seu programa e seu propósito" (CARROLL, 1998, p. 191). 
Vocês devem ter notado que eu não lidei com o segundo ponto da definição de arte de massa de Carroll que diz que a arte de massa é "Produzida e distribuída por uma tecnologia de massa". Inicialmente deixei-a de lado, porque, de certo ponto de vista, ela parece menos relevante em um universo artístico no qual quase todas as artes estão submetidas à distribuição de massa.

Em todo caso, isto não exclui o fato de que ela ainda é uma condição bastante decisiva. Do ponto de vista das transformações pelas quais a arte de massa passou, ela é a condição que foi sujeita às mais radicais transformações. Nesse sentido: nós nos movemos de um sistema de distribuição, centralizado e imposto, que era univocamente dirigido para o consumidor pelo produtor, no qual a margem de escolha do consumidor-usuário era mínima, para um ainda mais articulado sistema de distribuição que funciona por meio de múltiplos canais, permitindo ao usuário fazer uma escolha ativa. Isto era absolutamente impensável, não apenas na época de Adorno, mas até mesmo há vinte anos atrás.

E assim cai o último dos ídolos do discurso de Adorno acerca da arte de massa: o monolítico, unidirecional e totalmente homogeneizante caráter da produção de arte de massa. Aqui, as passagens da Dialética do Esclarecimento nesse sentido são tantas que é difícil saber qual escolher. Na visão de Adorno, a indústria da cultura produz bens que são absurdamente padronizados. Isto é requisitado não apenas pelas tecnologias que são utilizadas, como também revela um desejo explícito de dominar e homogeneizar. Por isso, para Adorno, não é apenas verdade que "porque milhões participam nela [na indústria cultural], certos processos de reprodução são necessários de modo que inevitavelmente requerem que necessidades idênticas, em inúmeros lugares, sejam satisfeitas com bens idênticos". Além disso, "supõe-se que o contraste técnico entre os poucos centros de produção e o grande número de pontos de consumo amplamente dispersos demandem organização e planejamento gerencial". Tudo isto é o resultado não apenas das demandas da tecnologia, mas de uma necessidade muito determinada de controlar e aniquilar a capacidade de o consumidor escolher livremente ${ }^{7}$. Nesta situação, o usuário é deixado sem a possibilidade de agir livremente: 'Não resta nada ao consumidor para classificar. Produtores fizeram-no por ele" e como resultado mesmo a "atividade mental do espectador" está proibida, na medida em que ele é forçado a consumir passivamente tudo o que o sistema centralizado propõe e que passa através de um número muito limitado de canais de comunicação que são orientados para a "reprodução de mais do mesmo" de modo que "se a

7 ADORNO. Dialectic of Enlightenment, p. 121.

8Ibidem, p. 125. 
maioria dos rádios e cinemas estivessem silenciados, muito provavelmente, os consumidores não sentiriam tanto sua perda". Hoje em dia, é muito difícil aceitar que as coisas ainda sejam assim. Quando Adorno estava escrevendo, o número disponível de canais de rádio e televisão podia ser contado em uma mão, mesmo nos Estados Unidos. Hoje em dia, há centenas deles em todo país avançado. Mas o que mais conta é que o consumidor pode escolher cada vez mais canais específicos que oferecem tipos precisos de produtos, às vezes destinados a um público limitado. Na medida em que esses serviços precisam ser pagos, esta soma, na maior parte das vezes modesta, inviabiliza a objeção esnobe de que não apreciamos aquilo pelo que não pagamos.

No mundo da televisão, essa transformação é possibilitada pelos novos meios digitais de comunicação, que abriram uma miríade de possibilidades onde antes reinava a tirania de frequências. Em meu país, por mais de duas décadas, nós só possuíamos a TV estatal, antes com um, depois dois, e, finalmente, três canais, e ela tinha uma abordagem decisivamente pedagógico-cultural; a chegada de estações privadas de televisão criou um novo modelo expressamente comercial ao qual a televisão pública imediatamente adaptou-se (e isto nos diz muito sobre o fato de que o nível da produção de massa não pode ser elevado, a não ser que o nível da cultura geral seja também maior: o público, tão logo ele pôde, deu as costas para a TV como instrumento pedagógico e escolheu o puro entretenimento, como se vinte anos de TV "educativa” não tivesse resultado algum). Finalmente, outros modelos de televisão entraram em cena e coexistem com a TV comercial, mesmo que eles ocupem uma posição minoritária: TV paga, pay-per-view etc.

$\mathrm{O}$ aspecto mais saliente dessas novas tecnologias é que elas permitem ao espectador, pela primeira vez, fazer uma escolha ativa: ele pode decidir seguir um canal que mostra séries de TV ou música clássica, filmes de arte, ou comédia romântica, e assim por diante.

Em outros campos artísticos, essa revolução que concede poder ao usuário é ainda mais evidente, pois ela não depende da escolha financeira que precisa ser feita para contratar uma assinatura. O fato de que tanta música e tantos filmes podem ser baixados da internet altera radicalmente a relação com o produto artístico, como ele era tradicionalmente, comparado com a arte de massa.

Tudo isto está começando a produzir uma mudança inesperada com respeito à questão da autoria ao tornar difícil para um autor assegurar seu direito de receber o pagamento do público por seu trabalho.

Por outro lado, isto torna mais fácil para um público restrito, mas constantemente crescente, gozar do acesso a obras que estavam inicialmente margina- 
lizadas pelas formas tradicionais de distribuição. Isto também permite a uma audiência muito maior fazer escolhas diretamente e, com isso, influenciar o que é disponibilizado para ela. A passagem da arte de massa para a arte sob medida já está produzindo um usuário mais bem informado, menos disposto a ser manipulado, mais alerta à qualidade dos produtos que estão em oferta. Nós estamos em meio a um processo de profunda mudança no modo como as pessoas consomem e isto é gerado por múltiplos meios de reprodução que estão agora disponíveis e que levam, cada vez mais, a um consumo individualizado de formas de arte que antes eram vivenciadas como rituais coletivos. Só precisamos pensar em como os filmes são assistidos agora solitariamente em um aparelho de DVD, em um computador ou mesmo em um smart-phone ${ }^{9}$.

Em um dos textos fundacionais do Romantismo alemão, Friedrich Schlegel comparou o mundo da modernidade a um tipo de "grande empório estético" (ästhetischen Kramladen) ${ }^{10}$, no qual as obras de todos os tipos e qualidades de cada época e cada país poderia ser encontrada. Na realidade, por dois séculos não fazemos nada mais do que acreditar que essa profecia seria realizada, apenas para perceber, com cada inovação tecnológica, quanto permanecia a ser feito para realizá-la completamente.

Talvez quando a arte sob medida vier a ser a forma prevalente de distribuição tecnológica de arte, sejamos capazes de olhar para a arte de massa como algo pertencendo ao passado e de pensar, finalmente, e um pouco mais corretamente, que o sonho de Schlegel - mesmo que ele o visse mais como um pesadelo do que como um sonho - tornou-se de fato realidade.

9Neste caso há também uma passagem em Adorno que prevê exatamente o posto: "A necessidade que poderia resistir ao controle central já foi suprimida pelo controle da consciência individual. $\mathrm{O}$ passo do telefone ao radio distinguiu claramente os papeis. O primeiro ainda permitia ao assinante interpretar o papel de sujeito, e era liberal. $\mathrm{O}$ último é democrático: ele transforma todos os participantes em ouvintes e os submete autoritariamente a transmitir programas que são todos exatamente os mesmos", pp. 121-122. Sobre as novas formas de uso da imagem,cf. LIPOVETSKY, G.; SERROY, J. L'écran globale. Du cinema au smartphone, Paris, Seuil, 2007.

10 Fr. SCHLEGEL. Über das Studium der griechischen Poesie, in Kritische Friedrich-Schlegel Ausgabe, Bd. I, pp. 222-223. A imagem do "grande bazar" e do "enorme supermercado" retorna muitas vezes no volume de Lipovetsky e Serroy L'esthétisation du monde, op. cit.

Recebido em: 19.08.2014 | Aprovado em: 26.08.2014

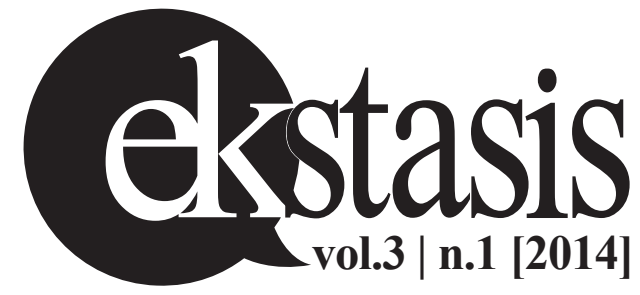

